\section{Effect of dietary treatment with olive oil by-product (olive cake) on physico- chemical, sensory and microbial characteristics of beef during storage}

\author{
Raffaella Branciari, ${ }^{1}$ David Ranucci, ${ }^{1}$ \\ Dino Miraglia, ${ }^{1}$ Stefania Urbani, ${ }^{2}$ \\ Sonia Esposto, ${ }^{2}$ Maurizio Servili ${ }^{2}$ \\ 'Department of Veterinary Medicine, \\ University of Perugia, Perugia; \\ ${ }^{2}$ Department of Agricultural, Food \\ and Environmental Sciences, University \\ of Perugia, Perugia, Italy
}

\section{Abstract}

Several studies have demonstrated that the use of natural preservatives through animal diets could increase the shelf life of meat and meat products since many plant-derived substances show antioxidant and antimicrobial properties. The aim of this work was to study the effect of olive cake dietary supplementation on beef oxidative stability and antimicrobial activity during storage. Beef cattle were randomly divided into three homogeneous groups that were assigned to one of the three diets: a commercial unified based diet administered for 90 days until slaughter (CTR), CTR diet supplemented with $0.5 \%$ olive cake administered for 90 days until slaughter (OC1), and CTR diet supplemented with $0.5 \%$ olive cake and administered for 60 days followed by the administration of the CTR diet for 30 days until slaughter (0C2). Beefsteaks were overwrapped with oxygen-permeable packaging and analysed at four different storage times (zero, three, six and nine days). At the four sampling times considered from all of the samples, total viable count (TVC), Enterobacteriaceae counts, colour coordinates (CIE L*a*b* colour system), peroxide value (PV), thiobarbituric reactive substances (TBARs) determinations and descriptive sensory analyses were performed. No differences in TVC and Enterobacteriaceae count were detected among the groups over all of the sampling times considered. Differences were recorder among groups for PV, TBARS, colour and sensory analysis. The addition of olive cake in the animal diet had an effect on lipid oxidation reducing the level of PV, TBARS and retarding colour deterioration and the development of off odour in $\mathrm{OC}$ meat during storage.

\section{Introduction}

Lipid oxidation is one of the main factors limiting the quality and acceptability of meat because it is responsible for the development of several alterations in meat, as well as for the production of potentially toxic compounds (Zanardi et al., 1998). Recently, particular attention as been paid to animal feed with natural antioxidants, aiming to guarantee the quality and safety of meat during storage (Descalzo and Sancho, 2008; Nieto et al., 2010). Furthermore, lipid oxidation is an important matter of concern to retailers because its discolouration effects, as well as off-odour and off-flavour development, strongly affect the meat's shelf life (Luño et al., 2000; Allen and Cornforth, 2010).

Among the different natural antioxidants used in animal nutrition (Insani et al., 2008; Ranucci et al., 2013, 2015; Branciari et al., 2015) olive oil by-products have been considered for their high content of phenolic substances (Novelli et al., 2014). In particular, olive cake, a mixture of skins, pulp, woody endcarp and seeds, is characterised by a high content in phenolic antioxidants, such as hydroxytyrosol (3,4-DHPEA), tyrosol ( $p$-HPEA) and secoiridoids derivatives, and in particular, the dialdehydic form of decarboxymethyl elenolic acid linked to 3,4-DHPEA or p-HPEA (3,4DHPEA-EDA or $p$-HPEA-EDA), and verbascoside (Servili et al., 2009). Furthermore the use of these bioactive compounds in food resulted in growth inhibition of different bacterial strains (Pereira et al., 2006; Fasolato et al., 2015). No data are currently available on the effects of dietary supplementation with olive cake on beef meat oxidative stability and microbial dynamics during storage.

The aim of this work was to evaluate the effect of dietary treatment with olive cake on beef oxidative stability during storage. The effect of antioxidants on microbial evolution was also studied.

\section{Materials and Methods}

The experiment was carried out using halfbreed beef cattle from a flock located in the Apulia Region (southern Italy). The beef cattle were randomly divided into three homogeneous groups of six animals each, balanced for age and body condition score. The three groups were assigned to one of the three diets: a commercial unified based diet administered for 90 days until slaughter (CTR), CTR diet supplemented with $0.5 \%$ olive cake and administered for 90 days until slaughter (OC1), and a CTR diet supplemented with $0.5 \%$ olive cake and administered for 60 days followed by the
Correspondence: Raffaella Branciari, Department of Veterinary Medicine, University of Perugia, via San Costanzo 4, 06126 Perugia (PG), Italy. Tel: +39.075.5857932 - Fax: +39.075.5857932

E-mail: raffaella.branciari@unipg.it

Key words: Natural antioxidant; Natural antimicrobial; Storage; Beef.

Conflict of interest: the authors declare no potential conflict of interest.

Received for publication: 25 August 2015. Revision received: 13 October 2015.

Accepted for publication: 13 October 2015 .

This work is licensed under a Creative Commons Attribution 3.0 License (by-nc 3.0).

(C) Copyright R. Branciari et al., 2015 Licensee PAGEPress, Italy

Italian Journal of Food Safety 2015; 4:5496 doi:10.4081/ijfs.2015.5496

administration of the CTR diet for 30 days until slaughter (0C2). The three diets were isoenergetic and isoproteic.

At the end of the experimental period, the animals were transported and slaughtered at a local slaughterhouse. Immediately after slaughter, the carcasses were promptly chilled to $7^{\circ} \mathrm{C}$ within $24 \mathrm{~h}$ and were then aged for 10 days at $0 \pm 2^{\circ} \mathrm{C}$. After aging, the Longissimus dorsi was removed, cut into steaks $2.0 \mathrm{~cm}$ thick, and were randomly assigned to retail packs with two steaks each, overwrapped with oxygen-permeable packaging and stored at $4 \pm 1^{\circ} \mathrm{C}$ for nine days in refrigerated display case with white fluorescent lighting (Lumos ${ }^{\circledR}$ LED up light 4000K, 908 lx; OSRAM spa, Milan, Italy). Meat samples packed were analysed at zero, three, six, and nine days for colour, total viable count (TVC), Enterobacteriaceae, thiobarbituric reactive substances (TBARS), peroxide value (PV) and sensory attributes. At zero days of storage, the olive cake phenolic compound content in the meat was evaluated and an increase in hydroxytyrosol (3,4DHPEA) content in 0C1 and 0C2 meat, with higher value in $0 \mathrm{Cl}$, was observed (data not reported). For the microbial analysis, about 25 gr of samples were collected at zero, three, six and nine days. Samples were placed in sterile and buffered peptone water (CM1049; 0xoid, Basingstoke, UK), and homogenised in a stomacher apparatus (Stomacher 400 circulator; Seward Ltd, Norfolk, UK) for two minutes at room temperature. Serial decimal dilutions in buffered peptone water were prepared and submitted to the following microbiological analyses: TVC determined using Plate Count Agar (CM0325; 0xoid) incubated at $30^{\circ} \mathrm{C}$ for 48 h (UNI EN ISO 4833:2004; ISO, 2004b), Enterobacteriaceae (ISO 21528-2:2004; ISO, 
2004a). After counting, the mean and standard deviation were calculated and data were reported as Log colony forming unit (CFU)/g.

A colour measurement was performed during each of the sampling intervals after a 30 min bloom period at refrigeration temperature using a CR400 Minolta chromameter (Minolta, Osaka, Japan) light source of D65 calibrated against a standard white tile. The results were expressed as redness $\left(a^{*}\right)$, hue value (tan-1 $\left.\mathrm{b}^{*} / \mathrm{a}^{*}\right)$ and saturation index, or chroma [ $\left(\mathrm{a}^{*} 2\right.$ $\left.+b^{*} 2\right) 1 / 2$ ], (CIE, 1986). For the evaluation of meat lipid oxidation, the peroxide value was determined during storage. The peroxide value (PV) was performed using Shantha and Decker's (1994) method slightly modified. Briefly fat from beef meat $(8 \mathrm{~g})$ was extracted with hexane-isopropanol $(3 / 2 \mathrm{v} / \mathrm{v})$. Of extracted lipids, $100 \mathrm{mg}$ were mixed with $9.5 \mathrm{~mL}$ chloroform/methanol $(7: 1, \mathrm{v} / \mathrm{v})$ and $50 \mathrm{~mL}$ of thiocyanate/Fe2+ solution and were then vortexed. The absorbance of the supernatant was measured at $500 \mathrm{~nm}$ using an Ultrospec 2100 pro UV/visible spectrometer (Amersham Pharmacia Biotech, Piscataway, NJ, USA). For the quantitative determination of PV, a Fe (III) standard calibration curve was constructed with samples containing 1-40 $\mu$ g Fe (III). The standard calibration curve obtained was $\mathrm{y}=0.0259 \mathrm{x}-0.0068\left(\mathrm{R}^{2}=0.9999\right)$ and $\mathrm{PV}$ was expressed as meq $0^{2} \mathrm{~kg}^{-1}$. The secondary lipid oxidation products of meat were assessed using the test of TBARs, according to Tarladgis et al. (1960), and the values were expressed as $\mathrm{mg}$ malondialdehyde (MDA)/kg meat.

A descriptive sensory analysis was performed using a six-member panel, which was trained following the criteria of ISO 85861:1993 (ISO, 1993). The attributes were gener-

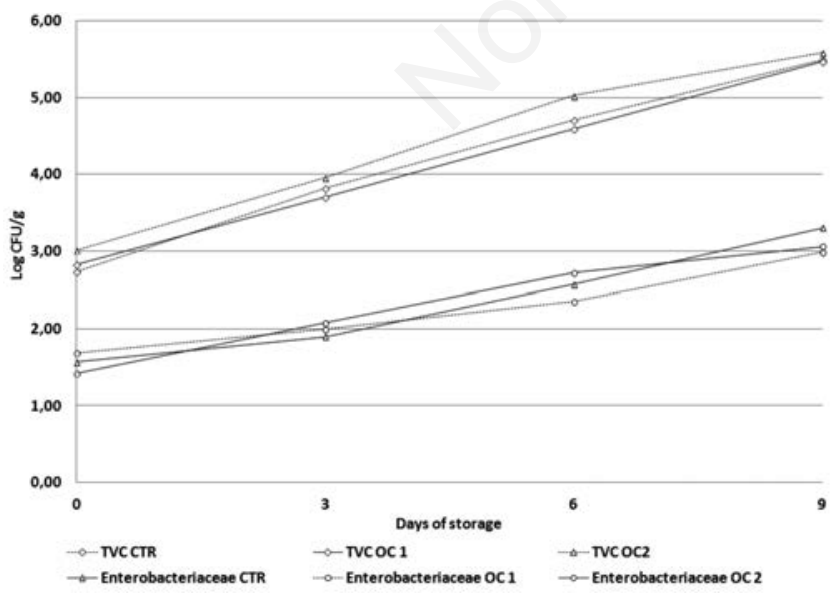

Figure 1. Microbial dynamics in beef steak during storage at $4 \pm 1^{\circ} \mathrm{C}$. TVC, total viable count; CTR, meat from cattle fed a standard diet; OC1, meat from cattle fed enriched diet with destoned olive cake for 90 days; OC2, meat from cattle fed enriched diet with destoned olive cake for 60 days. ated in three pre-testing sessions as described by Branciari et al. (2014). For quantification of the intensity of the attributes discolouration, red colour and off-odour, the panellist used a five-point descriptive scale according to ISO 13299:2003 (ISO, 2003).

The data were analysed using the GLM procedure of SAS (2001). An ANOVA model was used with diet (CTR, OC1 and OC2) as the fixed factor. The differences of the means were analysed using a Tukey test and were considered to be significant when $\mathrm{P}<0.05$.

\section{Results and Discussion}

No difference in TVC and Enterobacteriaceae was recorded among the different groups (Figure 1). The administration of OC-enriched diets to beef cattle did not seem to interfere with the microbial evolution of meat during storage. Some studies proved that this bioactive substance shows antimicrobial and antifungal activity in vitro or when directly added to food (Fasolato et al., 2015;
Medina et al., 2007; Brenes et al., 2007). Furthermore, feeding animals with natural bioactive compounds (10\% of distillate from rosemary leaves) (Nieto et al., 2010) was thought to delay the growth of total aerobic bacteria in lamb meat. This antimicrobial effect was not observed in this study.

The addition of the olive cake in the animal diet had an effect on lipid oxidation, and subsequently on colour, during beef storage (Figures 2-4).

0C1 beef was significantly redder (highest $a^{*}$ value) than were the other samples in all stages of storage $(\mathrm{P}<0.05)$. Furthermore, OC2 shows a higher $\mathrm{a}^{*}$ value than did CTR in all stages of storage except at nine days. The colour of the $0 \mathrm{C} 1$ beef loin steaks was a stable red throughout storage (Figure 2). OC2 steaks were less red than were $0 \mathrm{Cl}$ steaks, but were redder than were CTR till six days of storage.

The stability of saturation index and the hue-angle in OC meat samples confirmed the efficacy of the presence of OC polyphenol in meat in maintaining an attractive colour, which was evident in the $\mathrm{OC} 1$ sample (Figures 3 and 4). Differences between OC1 and CTR

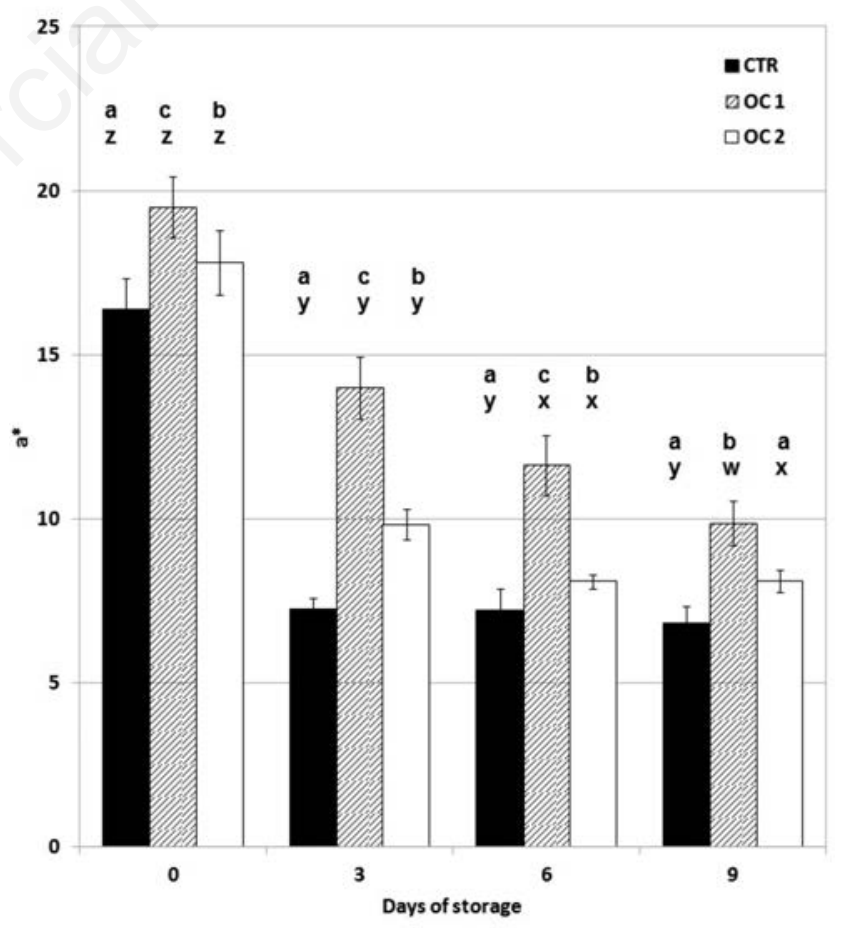

Figure 2. The effect of storage time on Commission Internationale de l'Eclairage $\mathrm{a}^{*}$ (redness) values of beef steak stored at $4 \pm 1^{\circ} \mathrm{C}$. CTR, meat from cattle fed a standard diet; $\mathrm{OC1}$, meat from cattle fed enriched diet with destoned olive cake for 90 days; $\mathrm{OC} 2$, meat from cattle fed enriched diet with destoned olive cake for $\mathbf{6 0}$ days. Values are means plus standard deviation. a'Within each day of storage, different superscripts indicate differences between dietary treatments $(P \leq 0.05){ }^{\mathrm{w}-\mathrm{z}}$ within each dietary treatment, different superscripts indicate differences between days of storage. 
were also confirmed after nine days of storage. The panel also confirmed the stability of the colour in 0C1 meat (Table 1), thus showing the effect of the polyphenol in retarding colour deterioration and extending the display life of fresh meat. The colour differences among the group may be due to the action of olive polyphenols that act as radical quenchers and metal chelators, probably interfering with the oxidation cycle at the propagation step, preventing additional lipid radicals from forming (Allen and Cornforth, 2010; Choe and Min, 2009). Likely, polyphenol limits the initiation of lipid oxidation by binding metals, such as iron and copper, stabilising them in an inactive or insoluble form. Meat colour can thus be preserved due to the antioxidant's ability to limit lipid oxidation, preventing the subsequent formation of reactive aldehydes and limiting iron-catalysed lipid oxidation (Allen and Cornforth, 2010; Dal Bosco et al., 2012). The

Table 1. Mean sensory values of beef steaks.

\begin{tabular}{|c|c|c|c|c|c|c|}
\hline \multirow{2}{*}{ Sensory values } & \multirow[t]{2}{*}{ Type of meat } & \multicolumn{4}{|c|}{ Days of storage } & \multirow[t]{2}{*}{ SEM } \\
\hline & & 0 & 3 & 6 & 9 & \\
\hline \multicolumn{7}{|l|}{ Off odour ${ }^{\circ}$} \\
\hline & CTR & $1.0^{\mathrm{aA}}$ & $2.0^{\mathrm{bB}}$ & $3.3^{\mathrm{bC}}$ & $5.0^{\mathrm{bD}}$ & 0.328 \\
\hline & $\mathrm{OCl}$ & $1.0^{\mathrm{aA}}$ & $1.0^{\mathrm{aA}}$ & $1.3^{\mathrm{aA}}$ & $3.0^{\mathrm{aB}}$ & 0.190 \\
\hline & OC2 & $1.0^{\mathrm{aA}}$ & $1.3^{\mathrm{aA}}$ & $3.0^{\mathrm{bB}}$ & $4.2^{\mathrm{bB}}$ & 0.287 \\
\hline \multicolumn{7}{|l|}{ Discolouration $^{\circ}$} \\
\hline & CTR & $1.5^{\mathrm{aA}}$ & $2.8^{\mathrm{bA}}$ & $4.3^{\mathrm{bB}}$ & $5.0^{\mathrm{bB}}$ & 0.306 \\
\hline & $\mathrm{OCl}$ & $1.0^{\mathrm{aA}}$ & $1.5^{\mathrm{aA}}$ & $2.5^{\mathrm{aB}}$ & $3.2^{\mathrm{aB}}$ & 0.221 \\
\hline & OC2 & $1.3^{\mathrm{aA}}$ & $2.5^{\mathrm{bB}}$ & $3.7^{\mathrm{bC}}$ & $5.0^{\mathrm{bD}}$ & 0.297 \\
\hline \multicolumn{7}{|l|}{ Red colour ${ }^{\#}$} \\
\hline & CTR & $1.8^{\mathrm{bA}}$ & $3.3^{\mathrm{bB}}$ & $4.3^{\mathrm{cD}}$ & $5.0^{\mathrm{bD}}$ & 0.268 \\
\hline & $\mathrm{OCl}$ & $1.0^{\mathrm{aA}}$ & $1.3^{\mathrm{aAB}}$ & $2.0^{\mathrm{aBC}}$ & $2.7^{\mathrm{aC}}$ & 0.150 \\
\hline & OC2 & $1.5^{\mathrm{abA}}$ & $2.8^{\mathrm{bB}}$ & $3.7^{\mathrm{bC}}$ & $4.5^{\mathrm{bD}}$ & 0.258 \\
\hline
\end{tabular}

SEM, standard error of mean; CTR, meat from cattle fed a standard diet; OCl, meat from cattle fed enriched diet with destoned olive cake for 90 days; OC2, meat from cattle fed enriched diet with destoned olive cake for 60 days. ${ }^{\circ}$ Scale: $1=$ none; $2=$ slight; $3=$ small; $4=$ moderate; $5=$ extreme. ${ }^{~}$ Scale: 1 denoted extremely intense red colour while 5 denoted extremely weak red colour. ${ }^{a-c} V a l u e s$ in the same column with different letters are significantly different $(\mathrm{P}<0.05)$; ${ }^{\mathrm{A} D}$ values in the same row with different letters are significantly different $(\mathrm{P}<0.05)$.

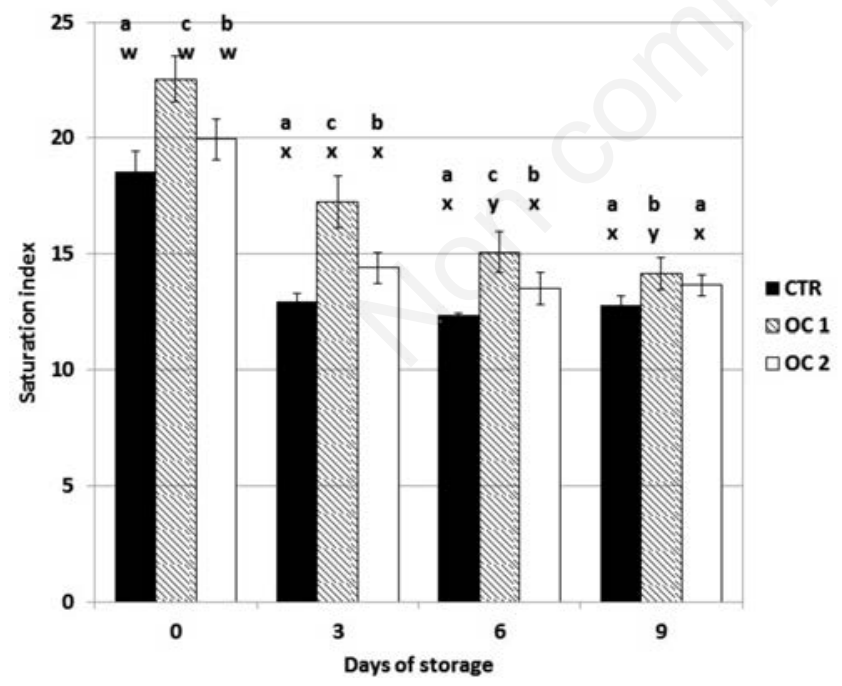

Figure 3. The effect of storage time on Saturation index of beef steak stored at $4 \pm 1^{\circ} \mathrm{C}$. CTR, meat from cattle fed a standard diet; OC1, meat from cattle fed enriched diet with destoned olive cake for 90 days; OC2, meat from cattle fed enriched diet with destoned olive cake for 60 days. Values are means plus standard deviations. ${ }^{\mathrm{a}-\mathrm{c}}$ Within each day of storage, different superscripts indicate differences between dietary treatments $(P \leq 0.05)$; ${ }^{\mathrm{w}-\mathrm{z}}$ within each dietary treatment, different superscripts indicate differences between days of storage.

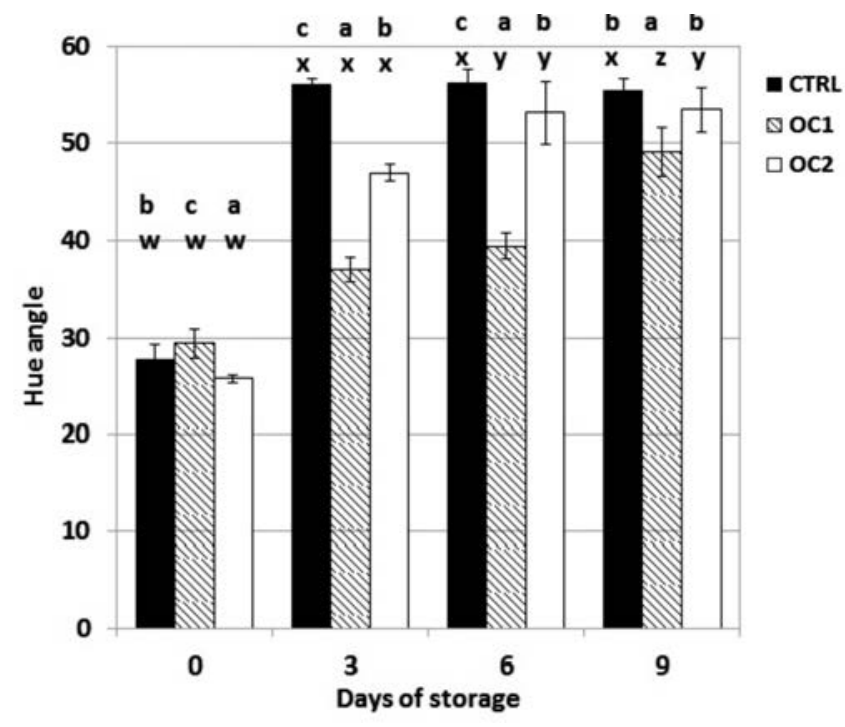

Figure 4. The effect of storage time on Hue angle of beef steak stored at $4 \pm 1^{\circ} \mathrm{C}$. CTR, meat from cattle fed a standard diet; $\mathrm{OC1}$, meat from cattle fed enriched diet with destoned olive cake for 90 days; OC2, meat from cattle fed enriched diet with destoned olive cake for $\mathbf{6 0}$ days. Values are means plus standard deviations. a'Within each day of storage, different superscripts indicate differences between dietary treatments $(P \leq 0.05){ }^{\mathrm{w}-\mathrm{z}}$ within each dietary treatment, different superscripts indicate differences between days of storage. 


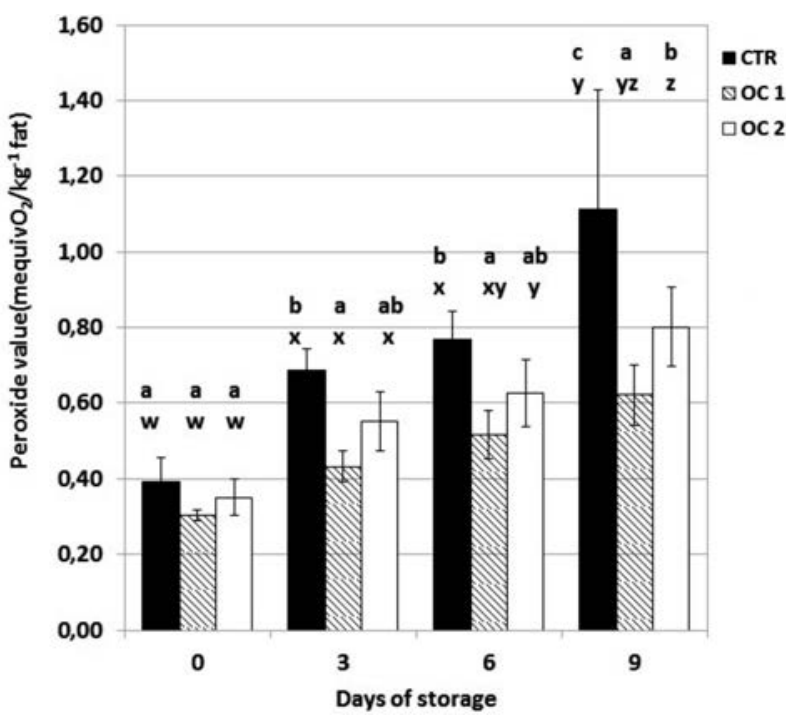

Figure 5. The effect of storage time on peroxide value (meq $\mathrm{O}^{2} \mathrm{~kg}^{-1}$ fat) of beef steak stored at $4 \pm 1^{\circ} \mathrm{C}$. CTR, meat from cattle fed a standard diet; $\mathrm{OC} 1$, meat from cattle fed enriched diet with destoned olive cake for 90 days; $\mathrm{OC} 2$, meat from cattle fed enriched diet with destoned olive cake for $\mathbf{6 0}$ days. Values are means plus standard deviations. ${ }^{a-c}$ Within each day of storage, different superscripts indicate differences between dietary treatments $(\mathrm{P} \leq 0.05)$; ${ }^{\mathrm{w}-\mathrm{z}}$ within each dietary treatment, different superscripts indicate differences between days of storage.

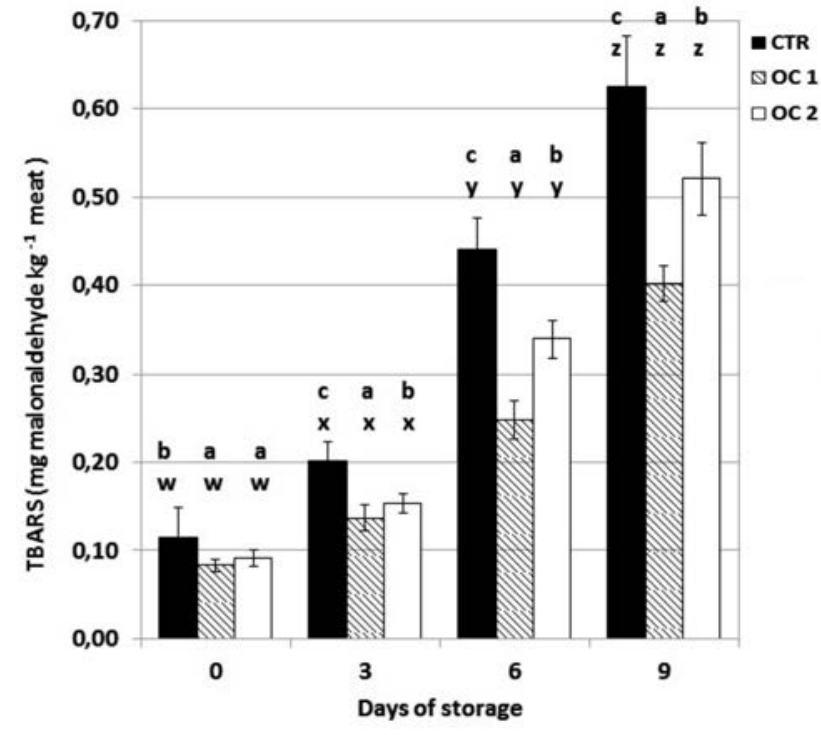

Figure 6. The effect of storage time on thiobarbituric reactive substances (mg MDA kg-1 meat) of beef steak stored at $4 \pm 1^{\circ} \mathrm{C}$. TBARS, thiobarbituric reactive substances; CTR, meat from cattle fed a standard diet; $\mathrm{OC} 1$, meat from cattle fed enriched diet with destoned olive cake for 90 days; OC2, meat from cattle fed enriched diet with destoned olive cake for $\mathbf{6 0}$ days. Values are means plus standard deviations. ${ }^{\mathrm{a}-\mathrm{c}}$ Within each day of storage, different superscripts indicate differences between dietary treatments $(P \leq 0.05)$; $^{\mathrm{w}-\mathrm{T}}$ within each dietary treatment, different superscripts indicate differences between days of storage. time to develop off-odours (Table 1) was also influenced by phenolic compounds, thus confirming the results of other studies that showed that off-flavours of beef were due to aldehydes produced during lipid oxidation. The higher presence of polyphenol substances in animal tissues probably affects the stability of lipids during meat storage, resulting in the delayed development of off-odour (Descalzo et al., 2008).

Phenolic compounds also positively contributed to the oxidative status of the meat of treated animals by reducing the level of PV and TBARS during storage in OC1 and OC2 meat, which was more evident in $0 \mathrm{Cl}$ meat (Figures 5 and 6 ). Other authors have also reported the beneficial effects of olive polyphenols on the oxidative status of meat (Dal Bosco et al., 2012; Luciano et al., 2013), demonstrating their antioxidant effect in meat of animals fed olive phenolic compounds.

\section{Conclusions}

The results of the experiment demonstrated that olive polyphenols used in livestock diets could favourably extend the storage of meat through delaying lipid oxidation and preserving meat colour stability even though no antimicrobial effect was observed. Further work will be needed to expand our understanding of the effect of these bioactive compounds in different packaging systems, influencing the shelf life of meat.

\section{References}

Allen K, Cornforth D, 2010. Comparison of spice-derived antioxidants and metal chelators on fresh beef color stability. Meat Sci 85:613-9.

Branciari R, Mughetti L, Ranucci D, Miraglia D, Valiani A, Acuti G, Selvaggini R, Trabalza Marinucci M, 2014. Influence of manufacturing procedure on the compositional and sensory properties of n-3 fatty acid enriched Pecorino cheese. J Dairy Res 29:1-7.

Branciari R, Ranucci D, Trabalza-Marinucci M, Codini M, Orru M, Ortenzi R, Forte C, Ceccarini MR, Valiani A, 2015. Evaluation of the antioxidant properties and oxidative stability of Pecorino cheese made from the raw milk of ewes fed Rosmarinus officinalis L. leaves. Int J Food Sci Tech 50:558-65.

Brenes M, Medina E, Romero C, De Castro A, 2007. Antimicrobial activity of olive oil. Agro Food Ind Hi Tec 4:6-8.

Choe E, Min DB, 2009. Mechanisms of antioxidants in the oxidation of foods. Compr Rev
Food Sci F 8:345-58.

CIE, 1986. Colorimetry 15.2. Commission Internationale de l'Eclairage Publ., Vienna, Austria.

Dal Bosco A, Mourvaki E, Cardinali R, Servili M, Sebastiani B, Ruggeri S, Mattioli S, Taticchi A, Esposto S, Castellini C, 2012. Effect of dietary supplementation with olive pomaces on the performance and meat quality of growing rabbits. Meat Sci 92:783-8.

Descalzo AM, Sancho AM, 2008. A review of natural antioxidants and their effects on oxidative status, odor and quality of fresh beef produced in Argentina. Meat Sci 79:423-36.

Fasolato L, Cardazzo B, Balzan S, Carrao L, Taticchi A, Montemurro F, Novelli E, 2015. Minimum bactericidal concentration of phenols extracted from oil vegetation water on spoilers, starters and food-borne bacteria. Ital J Food Safety 4:4519.

Insani EM, Eyherabide A, Grigioni G, Sancho AM, Pensel NA, Descalzo AM, 2008. Oxidative stability and its relationship with natural antioxidants during refrigerated retail display of beef produced in Argentina. Meat Sci 79:444-52.

ISO, 1993. Sensory analysis. General guidance for the selection, training and monitoring of assessors. Part 1: selected assessors. ISO Norm 8586-1:1993. International 
Organization for Standardization, Geneva, Switzerland.

ISO, 2003. Sensory analysis. Methodology: general guidance for establishing a sensory profile. ISO Norm 13299:2003. International Organization for Standardization, Geneva, Switzerland.

ISO, 2004a. Microbiology of food and animal feeding stuffs. Horizontal methods for the detection and enumeration of Enterobacteriaceae. Part 2: colony-count method. ISO Norm 21528-2:2004. International Organization for Standardization, Geneva, Switzerland.

ISO, 2004b. Microbiology of food and animal feeding stuffs. Horizontal method for the enumeration of microorganisms. Colonycount technique at 30 degrees C. ISO Norm 4833:2004. International Organization for Standardization, Geneva, Switzerland.

Luciano G, Pauselli M, Servili M, Mourvaki E, Serra A, Monahan FJ, Lanza M, Priolo A, Zinnai A, Mele M, 2013. Dietary olive cake reduces the oxidation of lipids, including cholesterol, in lamb meat enriched in polyunsaturated fatty acids. Meat Sci 93:703-14.

Luño M, Roncalés P, Djenane $\mathrm{D}$, Beltràn JA, 2000. Beef shelf life in low 02 and high C02 atmosheres containing different low
C0 concentrations. Meat Sci 55:413-9.

Medina E, Romero C, Brenes M, de Castro A, 2007. Antimicrobial activity of olive oil, vinegar, and various beverages against foodborne pathogens. J Food Protect 70:1194-9.

Nieto G, Díaz P, Bañón S, Garrido MD, 2010. Dietary administration of ewes diets with a distillate from rosemary leaves (Rosmarinus officinalis L): influence on lamb meat quality. Meat Sci 84:23-9.

Novelli E, Fasolato L, Cardazzo B, Carraro L, Taticchi A, Balzan S, 2014. Addition of phenols compounds to meat dough intended for salami manufacture and its antioxidant effect. Ital J Food Safety 3:1704.

Pereira JA, Pereira APG, Ferreira ICFR, Marcelino F, Valentão P, Andrade PB, Seabra R, Estevinho L, Bento A, Alberto Pereira J, 2006. Table olives from Portugal: phenolic compounds, antioxidant potential and antimicrobial activity. J Agr Food Chem 54:8425-31.

Ranucci D, Beghelli D, Trabalza-Marinucci M, Branciari R, Forte C, Olivieri 0, Badillo Pazmay GV, Cavallucci C, Acuti G, 2015. Dietary effects of a mix derived from oregano (Origanum vulgare L.) essential oil and sweet chestnut (Castanea sativa mill.) wood extract on pig performance, oxidative status and pork quality traits. Meat Sci
100:319-26.

Ranucci D, Branciari R, Acuti G, Della Casa G, Trabalza-Marinucci M, Miraglia D, 2013. Quality traits of ciauscolo salami from meat of pigs fed rosemary extract enriched diets. Ital J Food Safety 2:e16.

SAS, 2001. Statistical software and user's guide, version 8.2. SAS Institute, Inc., Cary, NC, USA.

Servili M, Esposto S, Fabiani R, Urbani S, Taticchi A, Mariucci F, Selvaggini R, Montedoro GF, 2009. Phenolic compounds in olive oil: antioxidant, health and organoleptic activities according to their chemical structure. Inflammopharmacology 17:1-9.

Shanta NC, Decker EA, 1994. Rapid, sensitive, iron-based spectrophotometric methods for determination of peroxide values of food lipids. J AOAC Int 77:421-4.

Tarladgis BG, Watts BM, Yonathan M, 1960. Distillation method for the determination of malonaldehyde in rancid foods. J Am Oil Chem Soc 37:44-8.

Zanardi E, Novelli E, Nanni N, Ghiretti P, Delbono G, Campanini G, Dazzi G, Madarena G, Chizzolini R, 1998. Oxidative stability and dietary treatment with vitamine E, oleic acid and copper of fresh and cooked pork chop. Meat Sci 42:309-20. 